\title{
Comparison between Different Shades of Monolithic Zirconia over Microhardness and Water Solubility and Sorption of Dual-cure Resin Cement
}

\author{
Soni Kumari ${ }^{1}$, Nikita Raman ${ }^{2}$, Sarika Sharma ${ }^{3}$, Ashish K Srivastava ${ }^{4}$, Gunja $^{5}$, Arunendra S Chauhan ${ }^{6}$
}

\begin{abstract}
Aim and objective: To compare the different shades of monolithic zirconia over microhardness and water solubility and water sorption of dual-cure resin cement.

Materials and methods: Eighty specimens were included in the study. They were categorized into four categories having 20 samples each. Category one: No ceramic disks were present in the control group; the cement was directly activated. Category two: Curing of the resin cement with one shade of monolithic zirconia topping. Category three: Curing of the resin cement with an overlaying layer A monolithic zirconia version with two shades. Category four: Curing of the resin cement with an overlaying layer A three-tone monolithic zirconia version. In each category, two subgroups were further created $(n=10)$. One subgroup consisted of conventional dual-cure resin-based cement, while the other subgroup consisted of selfadhesive dual-cure resin-based cement. Vickers microhardness, water solubility, and water sorption of resin cement sorption were precisely measured after 24 hours of storage in an incubator at $37^{\circ} \mathrm{C}$. The statistical analysis was undertaken with the help of statistical tests like two-way analysis of variations (ANOVA), one-way ANOVA, independent $t$-tests, Tukey's test, and Tamhane's T2 test. The $p \leq 0.05$ was considered statistically significant. Results: Microhardness was more excellent in conventional dual-cure resin-based cement in comparison with self-adhesive dual-cure cement. At the same time, the water solubility and water sorption were lower in conventional dual-cure resin-based cement than self-adhesive dualcure resin cement. The effect of shade of monolithic variant of zirconia was significant over the microhardness of both dual-cure resin-based cement; however, the impact was nonsignificant over the water solubility and water sorption of the resin-based resin cement. Further, it was also observed that the use of a monolithic variant of zirconia led to a decrease in microhardness of both dual resin-based cement in comparison to the condition when no ceramics were used.
\end{abstract}

Conclusion: The effect of shade of monolithic variant of zirconia was statistically significant over the microhardness of both dual-cure resin-based cement; however, the result was not significant over the water solubility and water sorption of the resin-based cement. The use of a monolithic variant of zirconia led to a decrease in the microhardness of both dual resin-based cement compared to the condition when no ceramics were used. Clinical significance: The quantity of polymerization in resin-based cement affects their clinical effectiveness for a more extended period. It is believed that the measurement of microhardness is a reliable and straightforward process for evaluating the amount of polymerization of resin-based cement. Very few studies have been conducted in the past to compare the shades of monolithic zirconia over the microhardness, water solubility, and water sorption of the dual-cure resin-based cement.

Keywords: Dual-cure resin cement, Microhardness, Monolithic zirconia, Shade.

The Journal of Contemporary Dental Practice (2021): 10.5005/jp-journals-10024-3178

\section{INTRODUCTION}

Zirconia crowns and bridges quickly become the most popular dental crown and restoration material because of their exceptional esthetics, biocompatibility and longevity, and good strength. Patients have indeed been asking for milled zirconia restorations to replace porcelain-fused-to-metal (PFM) restorations since the advent of milled zirconia restorations. When restoring a single tooth, some dentists only utilize zirconia. Most dental professionals are moving away from traditional PFM and all-ceramic crowns and focusing toward zirconia for fixed dental prostheses. ${ }^{1}$

The most frequent drawback of using $\mathrm{ZrO}_{2}$ (zirconia) restorations is the chipping of restorations. To overcome this disadvantage, a monolithic variant of zirconia has been introduced recently. Cementation of these monolithic variants of zirconia can be carried out with the help of both adhesive cement and conventional cement. ${ }^{2}$ Adhesive cement, on the contrary, has been more widely approved for the cementation of these restorations. These cement have properties like reduced solubility, decreased incidence of marginal leakage, greater strength, and improved esthetics features. ${ }^{3}$

Since the monolithic variant of zirconia is semitranslucent, there can be a decrease in the light crossing through them. It can have a
${ }^{1}$ Department of Prosthodontics, Crown and Bridge and Implantology, New Delhi, India

${ }^{2}$ Department of Dentistry, Anugrah Narayan Magadh Medical College and Hospital, Gaya, Bihar, India

${ }^{3}$ Department of Dentistry, Government Medical College, Ratlam, Madhya Pradesh, India

${ }^{4}$ Department of Prosthodontics, Crown and Bridge, Hazaribag College of Dental Science and Hospital, Hazaribag, Jharkhand, India

${ }^{5}$ Department of Oral Pathology, Buddha Institute of Dental Science and Hospital, Patna, Bihar, India

${ }^{6}$ Department of Public Health Dentistry, Uttaranchal Dental and Medical Research Institute, Dehradun, Uttarakhand, India

Corresponding Author: Nikita Raman, Department of Dentistry, Anugrah Narayan Magadh Medical College and Hospital, Gaya, Bihar, India, Phone: +91 9304518574, e-mail: nikitaraman07@gmail.com

How to cite this article: Kumari S, Raman N, Sharma $\mathrm{S}$, et al. Comparison between Different Shades of Monolithic Zirconia over Microhardness and Water Solubility and Sorption of Dual-cure Resin Cement. J Contemp Dent Pract 2021;22(9):1019-1024.

Source of support: Nil

Conflict of interest: None

() The Author(s). 2021 Open Access This article is distributed under the terms of the Creative Commons Attribution 4.0 International License (https://creativecommons. org/licenses/by-nc/4.0/), which permits unrestricted use, distribution, and non-commercial reproduction in any medium, provided you give appropriate credit to the original author(s) and the source, provide a link to the Creative Commons license, and indicate if changes were made. The Creative Commons Public Domain Dedication waiver (http://creativecommons.org/publicdomain/zero/1.0/) applies to the data made available in this article, unless otherwise stated. 
negative effect on the typical polymerization of the cement, which is based on dual-cure resins. This can lead to inadequate mechanical properties of the cement-like inadequate microhardness of the resin cement, increase in the sorption of water, and increase in the cement's solubility. ${ }^{4}$ It has been found that an increase in water sorption and water solubility is more commonly observed in the case of resin cement that is self-adhesive compared to conventional cement; this can be attributed to the use of monomers in this cement. According to Samimi et al., the efficacy of polymerization in dual-cure cement is influenced by several parameters such as the intensity of light used for curing, time used for irradiation, the transmission of light and shade, thickness, and type of ceramics used..$^{5}$ Most of the time, it has been observed that other factors neutralize the negative impact of one factor. However, it has been found that the optimal microhardness of dual-cure resin-based cement affected due to reduced polymerization due to reduced light transmission is not compensated by the chemical constituents of the dual-cure resins. ${ }^{6}$ In the past, several research workers had carried out research to inquire about the impact of ceramics on the attenuation of light passing through them and its influence over the mechanical properties of the dual-cure resin-based cement present beneath these ceramic restorations. ${ }^{7}$ These studies used ceramics of different types, different thicknesses, different shades, and different light protocols. It is also found that reduced transmission of light through ceramics due to any reason can cause a decrease in the strength and increase in the water sorption and water solubility of the resin-based cement present beneath these indirect ceramicbased restorations affecting their overall success. ${ }^{8}$

Studies conducted previously had reflected that the thickness of ceramics has more influence on the light transmission than the shade of ceramics. However, in a study conducted by Passos et al., it has been found that the dual curing percentage of conventional dual-cure resin-based cement was decreased on increasing the chroma saturation in feldspathic disks of a low thickness (less than $2 \mathrm{~mm}) .{ }^{9}$ Duran et al. also conducted a study and found that the amount of irradiation of light decreased in hybrid ceramic samples of all thicknesses, increasing the darkness of the hybrid ceramics. The results of this study were in accordance with the results of the study conducted by llie and Stawarczyk. ${ }^{10}$

In all these previous studies, it was observed that there had been no focus on changes in the water solubility, water sorption, and microhardness in underlying dual-cure resin cement in different shades of monolithic zirconia crowns. Because the adhesive cement's properties can have a direct impact on the overall success of monolithic zirconia restorations, this study was conducted to assess the impact of different shades of monolithic zirconia on microhardness, as well as water sorption and solubility of both conventional and self-adhesive dual-cure resin-based cement.

\section{Materials and Methods}

The study was conducted at a tertiary-level dental hospital in New Delhi. Clearance was obtained from the ethical committee. The reference no for ethical approval was NMC/2020/11/168.

\section{Preparation of Monolithic Variant of Zirconia Specimens}

In this study, 60 specimens of monolithic variants of zirconia disks (Zircostar, Hungary), which were highly translucent and precolored, were taken for the analysis. The dimensions of the disks were kept identical for each study specimen. The measurements were $10 \mathrm{~mm}$ in diameter and $1 \mathrm{~mm}$ in thickness. Initially, the disks were milled with these dimensions in three different shades, namely A one, A two, and $A$ three $(n=10)$, with the help of computer-aided manufacturing and computer-aided designing machine. After this, a digital caliper was used to measure the thickness of each specimen. If there was a difference in thickness, the specimen was processed with silicon carbide grinding paper to ensure that all of the research specimens had the same thickness. However, if the discrepancy was more significant than $0.1 \mathrm{~mm}$, then that specimen was not included, though there were no such specimens in which such differences were found. Following that, the research specimens were sinterized for 8 hours at a temperature of $1450^{\circ} \mathrm{C}$, as per the manufacturer's instructions. Then, overglazing (Ivoclar Vivadent) was carried out on one surface. The specimens of the monolithic zirconia were cleaned using an ultrasonic scaler and distilled water before testing for 15 seconds. After cleaning, they were individually dried in the air for 30 seconds.

\section{Preparation of Dual-cure Resin Samples}

In this study, 80 samples of resin-based cement were prepared. They were prepared by putting conventional dual-cure resin cement and self-adhesive dual-cure resin cement in different silicon molds, which were cylindrical. The diameter of the molds was $8 \mathrm{~mm}$, while the thickness was $1 \mathrm{~mm}$. The calculations for the size of the sample were carried out according to the study results conducted by Kim et al. ${ }^{11}$ The mixing of the catalyst paste and base paste of the resin-based cement was done in the ratio of 1:1. Then, they were placed inside the molds. After that transparent mylar strip was kept over the filled orifice, followed by the placement of a glass slab. The purpose of the placement of mylar strip was to create separation between ceramics and cement and to produce a smooth and even surface of resin-based cement that was required for analyzing Vickers microhardness. The glass slab was removed, and then there was light curing of the specimens. Light curing of the resin cement was done with the help of LED (Woodpecker). The irradiance used was $1200 \mathrm{~mW} / \mathrm{cm}^{2}$ for 20 seconds. Curing was done as per the following arrangements:

Category one: No ceramic disks were present; there was direct activation. It was the control group

Category two: Curing of the resin cement with overlying, one shade of monolithic variant of zirconia

Category three: Curing of the resin cement with overlying, A two shade of monolithic variant of zirconia

Category four: Curing of the resin cement with overlying A three shade of monolithic variant of zirconia

In each category, two subgroups were further created $(n=10)$. One subgroup consisted of conventional dual-cure resin-based cement, while the other subgroup consisted of self-adhesive dualcure resin-based cement. The tip of the light-curing unit was placed over the mylar strips in control groups. In contrast, it was placed directly over the monolithic variant of zirconia's glazed surface in experimental categories. The curing was carried out for 20 seconds. The specimens were removed from the cylindrical silicone molds 15 minutes after the beginning of the light-curing process.

To remove flashes, silicon carbide paper was used for finishing the periphery of the resin cement specimens. Lightproof containers were used to store the samples. The temperature of the storage was $37^{\circ} \mathrm{C}$, while the duration of the storage was 24 hours. With the use of a surface microhardness tester, the Vickers microhardness of the resin cement specimens was measured (SCTMC). The load adjusted 
on the tester was $50 \mathrm{~g}$, equivalent to 0.49 Newton force. This load was applied at every specimen's bottom surface for 15 seconds. There was the creation of three indentations in every specimen, and the mean of the values was calculated for every sample.

\section{Measurement of Water Sorption and Water Solubility}

The study specimens of resin cement were placed along with dry fresh silica gel in a desiccator at a temperature of $37^{\circ} \mathrm{C}$ for 22 hours (Fig. 1). Afterward, the resin cement specimens were transferred to another desiccator at a temperature of $23^{\circ} \mathrm{C}$ for 2 hours. Then, there was the measurement of weight of the sample after every 20 hours with the help of electronic balance until the loss of mass was not more than $0.1 \mathrm{mg}$ in 24 hours (Fig. 2). The measurements continued till the reading was constant. This weight was recorded and considered as mass (W1). With the use of a digital caliper in millimeters, the thickness $(H)$ and diameter $(D)$ of all specimens were recorded. Then using these measurements, the volume $(V)$ of each sample was calculated with the help of the following formula:

where,

$$
V=\pi \times(D / 2)^{2} \times H
$$

$$
\begin{aligned}
& \pi=3.14 \\
& D=\text { Diameter of the specimen in } \mathrm{mm} \\
& H=\text { Thickness of the specimens in } \mathrm{mm}
\end{aligned}
$$

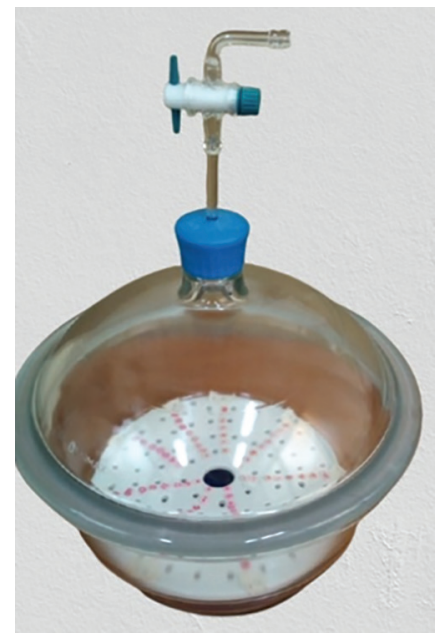

Fig. 1: Specimen of monolithic zirconia placed in a desiccator

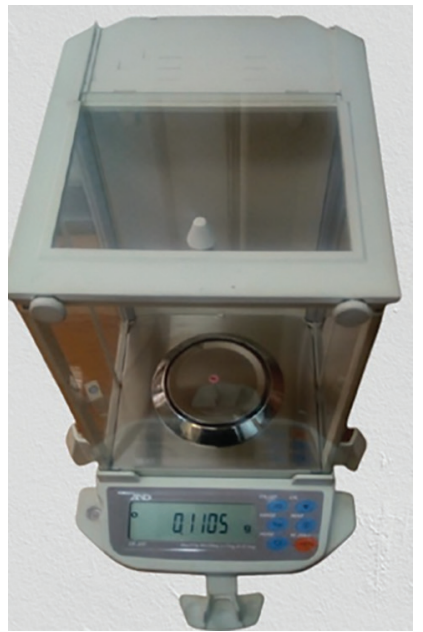

Fig. 2: Weighting the specimen in an electronic balance
Then the specimens were kept immersed in distilled water in the lightproof glass at a temperature of $37^{\circ} \mathrm{C}$ for 7 days. To avoid large changes in the $\mathrm{pH}$ of the distilled saline in which the specimens were immersed, the distilled water was replenished every 20 hours. Then the study samples of resin cement were removed from distilled water followed by gentle washing and blotting with soft, absorbent paper. Weight was measured at this stage, and it was considered as mass (W2). The study specimens were air-dried and transferred to the desiccators. Their weight was measured at regular intervals till a constant reading was obtained. This reading was recorded as mass (W3).

The water sorption (WS) of the study specimens was calculated using the following formula:

$$
W S=\frac{W 1-W 3}{V} \mu g / \mathrm{mm}^{3}
$$

The water solubility (WSL) of the study specimens was calculated using the following formula:

$$
W S L=\frac{W 2-W 3}{V} \mu g / \mathrm{mm}^{3}
$$

\section{Statistical Analysis}

The statistical analysis was undertaken with the help of statistical tests like two-way analysis of variations (ANOVA), one-way ANOVA, independent $t$-tests, Tukey's test, and Tamhane's T2 test. $p \leq 0.05$ was considered statistically significant.

\section{Results}

As the measurements and data for microhardness of resin cement were analyzed, it was discovered that microhardness reduced in all shades of monolithic zirconia variants when compared to the control group. In the present study, the microhardness of conventional dual-cure resin cement was greater than that of self-adhesive dual-cure resin-based cement. The difference was statistically significant with $p \leq 0.05$. When the effect of shade of monolithic variant of zirconia was analyzed, it was found that the difference in microhardness of both resin cement on using different shades was statistically significant (Table 1).

In the next step, there were measurements and data analysis obtained for water sorption of resin cement. It was found that water sorption increased in all shades of monolithic variants of

Table 1: Data comparing the mean values and standard deviation values of microhardness in different resin cement under various shades of monolithic variants of zirconia

\begin{tabular}{lccc}
\hline & \multicolumn{2}{c}{$\begin{array}{c}\text { Microhardness of two types of cement } \\
\text { used }\end{array}$} \\
\cline { 2 - 3 } $\begin{array}{l}\text { The shade of } \\
\text { monolithic variant } \\
\text { of zirconia }\end{array}$ & $\begin{array}{c}\text { Dual-cure self- } \\
\text { adhesive cement } \\
\text { (mean } \pm \text { S.D) }\end{array}$ & $\begin{array}{c}\text { Dual-cure } \\
\text { conventional } \\
\text { cement (mean } \pm \text { S.D) }\end{array}$ & $p^{\wedge}$ value \\
\hline No ceramic & $31.25 \pm 0.81$ & $71.61 \pm 4.51$ & $0.02^{\mathrm{s}}$ \\
A one shade & $6.89 \pm 0.53$ & $52.92 \pm 4.84$ & $0.01^{\mathrm{s}}$ \\
A two shade & $7.22 \pm 0.92$ & $51.17 \pm 3.65$ & $0.03^{\mathrm{s}}$ \\
A three shade & $8.19 \pm 0.71$ & $44.31 \pm 4.33$ & $0.01^{\mathrm{s}}$ \\
$p^{\#}$ & $0.01^{\mathrm{s}}$ & $0.03^{\mathrm{s}}$ & \\
\hline
\end{tabular}

Arepresents independent $t$-test values;" values, ${ }^{s}$ represents statistically significant 
zirconia in comparison to the control group in self-adhesive dualcure cement. There was no significant change in water sorption of conventional cement in comparison to the control groups. When the water sorption of self-adhesive dual-cure resin-based cement and conventional dual-cure resin cement was compared, it was discovered that conventional dual-cure resin cement had less water sorption than self-adhesive dual-cure cement. The difference was statistically significant with $p \leq 0.05$. When the effect of shade of monolithic variant of zirconia on water sorption of resin was analyzed, it was found that the difference in water sorption of both resin cement using different shades was statistically nonsignificant (Table 2).

Finally, there were measurements and analyses of data obtained for the water solubility of resin cement. It was found that water solubility increased in different shades of monolithic variants of zirconia in comparison to the control group in selfadhesive dual-cure cement. There was no significant change in water solubility of conventional cement in comparison to control groups. When the effect of shade of monolithic variant of zirconia on the water solubility of resin cement was analyzed, it was found that the difference in water solubility of both the resin cement on using different shades was statistically nonsignificant. When the water solubility of self-adhesive dual-cure resin-based cement and conventional dual-cure resin cement was compared, it was discovered that conventional dual-cure resin cement had less water solubility than self-adhesive dual-cure cement. The difference was statistically significant with $p \leq 0.05$ (Table 3 ).

Table 2: Data comparing the mean values and standard deviation values of sorption of water in different resin cement under various shades of monolithic variants of zirconia

\begin{tabular}{lccc}
\hline \multirow{4}{*}{$\begin{array}{l}\text { The shade of } \\
\text { monolithic variant of } \\
\text { zirconia }\end{array}$} & $\begin{array}{c}\text { Type of cement used } \\
\text { adhesivecement } \\
\text { (mean } \pm \text { S.D) }\end{array}$ & $\begin{array}{c}\text { Dual-cure } \\
\text { conventional cement } \\
\text { (mean } \pm \text { S.D) }\end{array}$ & $p^{\wedge}$ value \\
\hline No ceramic & $46.34 \pm 9.57$ & $29.37 \pm 7.94$ & $0.01^{\mathrm{s}}$ \\
A one shade & $67.24 \pm 22.62$ & $28.20 \pm 5.64$ & $0.03^{\mathrm{s}}$ \\
A two shade & $65.80 \pm 23.74$ & $29.12 \pm 10.63$ & $0.02^{\mathrm{s}}$ \\
A three shade & $66.15 \pm 10.31$ & $32.53 \pm 7.69$ & $0.01^{\mathrm{s}}$ \\
$p^{\#}$ & 0.741 & 0.723 & \\
\hline
\end{tabular}

$\wedge$ represents independent $t$-test values; ${ }^{\#}$ represents one-way ANOVA F-test values; ${ }^{s}$ represents statistically significant

Table 3: Data comparing the mean values and standard deviation values of solubility of water in different resin cement under various shades of monolithic variants of zirconia

\begin{tabular}{lccc}
\hline \multirow{2}{*}{$\begin{array}{l}\text { The shade of } \\
\text { monolithic } \\
\text { variant of zirconia }\end{array}$} & $\begin{array}{c}\text { Type of cement used } \\
\text { adhesive cement } \\
\text { (mean } \pm \text { S.D) }\end{array}$ & $\begin{array}{c}\text { Dual-cure } \\
\text { conventionalcement } \\
\text { (mean } \pm \text { S.D) }\end{array}$ & $p^{\wedge}$ value \\
\hline No ceramic & $10.54 \pm 3.99$ & $2.46 \pm 1.97$ & $0.02^{\mathrm{s}}$ \\
A one shade & $31.60 \pm 9.38$ & $2.11 \pm 4.65$ & $0.04^{\mathrm{s}}$ \\
A two shade & $31.34 \pm 7.36$ & $2.60 \pm 4.39$ & $0.01^{\mathrm{s}}$ \\
A three shade & $29.82 \pm 7.68$ & $2.76 \pm 3.37$ & $0.03^{\mathrm{s}}$ \\
$p^{\#}$ & 0.876 & 0.675 & \\
\hline${ }^{\#}$ & &
\end{tabular}

$\wedge$ represents independent $t$-test values; ${ }^{\#}$ represents one-way ANOVA $F$-test values; ${ }^{s}$ represents statistically significant

\section{Discussion}

Nowadays, zirconia restorations have become the primary choice for the patient and the dental professionals for fixed restorations because of their excellent esthetics and good biocompatibility. However, chipping off has been reported in some restorations of zirconia. Monolithic zirconia has been introduced to mitigate this drawback. For monolithic zirconia cementation, both conventional and adhesive cement are employed; however, adhesive cement is most usually used. The most common adhesive cement used is dual-cure adhesive cement and conventional self-adhesive cement. These cement have the properties like greater strength, improved esthetics, and decreased incidence of marginal leakage. ${ }^{11}$

For the complete success of the zirconia restoration, there is a need for good mechanical properties of the zirconia and adhesive cement. Therefore, in the present study, monolithic zirconia, dualcure adhesive cement, and conventional self-adhesive cement were included to evaluate the mechanical properties of adhesive cement-like microhardness, water solubility, and water sorption in different shades of zirconia. Although the thickness of zirconia crowns on the polymerization of underlying adhesive cement has been studied, the effect of shade of monolithic zirconia on water solubility, water sorption, and microhardness in underlying adhesive cement has not been studied. Therefore, this study was undertaken with the ambition of evaluating the impact of various shades of a monolithic variant of zirconia over the microhardness and water sorption and water solubility of both conventional and self-adhesive dual-cure resin-based cement. ${ }^{12}$

It was found that microhardness was greater in conventional dual-cure resin-based cement in comparison with self-adhesive dual-cure cement. At the same time, the water solubility and water sorption were lower in conventional dual-cure resin-based cement than self-adhesive dual-cure resin cement. The effect of shade of monolithic variant of zirconia was significant over the microhardness of both dual-cure resin-based cement; however, the effect was not significant over the water solubility and water sorption of the resin-based cement. Furthermore, when a monolithic form of zirconia is employed, the microhardness of both dual resin-based cement and dual-cure resin-based cement is reduced compared to when no ceramics are used, and there is direct activation of the dual-cure resin-based cement. This may be due to the reason that there may be increased attenuation of the light passing through the intervening monolithic variant of zirconia. $^{13,14}$

Ansarifard et al. conducted a study to evaluate the role of shade of monolithic variant of the zirconia restoration in the microhardness, water solubility, and water sorption of the underlying dual-cure resin-based cement. ${ }^{15}$ The results found in this study were in accordance with the present study. Ilie and Stawarczy conducted a study to evaluate the quantity of light passing through the monolithic variant of zirconia having a different thickness in different polymerization conditions. They found that that there is a reduced transmission of light through the monolithic variant in comparison with the conventional zirconia. ${ }^{16}$ These results are in accordance with the current study results where it was found that there may be reduced transmission of light through the monolithic variant of zirconia.

Sulaiman et al. also conducted a study to evaluate the transmission of light through different esthetic indirect restorations, including the monolithic variant of zirconia. It was found that there was increased attenuation of light passing through the monolithic 
variant of zirconia. ${ }^{17}$ The results are in accordance with the results of the current study. Besides other studies conducted in the past by Borge et al., Sokolowski et al. and Kesrak et al. showed that microhardness of the resin cement is more significant when there are direct means of light activation. . $^{18,19}$

Pazi et al. conducted a study and found no significant difference in light transmission through the Leucite disk and zirconia disk. ${ }^{20,21}$ The results are not in accordance with the results found in the current study, where it was observed that the microhardness of the resin cement is more significant when there are direct means of light activation. Such difference in the results may be due to the difference in the thickness and type of the zirconia specimen used. In our study, monolithic zirconia was used with a thickness of $1 \mathrm{~mm}$, while in the study conducted by Pazi et al., conventional zirconia was used, having a thickness of $1.5 \mathrm{~mm}$.

Gültekin et al. performed a study to analyze the amount of polymerization and microhardness of self-adhesive dual-curebased cement beneath the zirconia restorations and found that the curing was not optimal. These results are in accordance with the results of our study. ${ }^{22,23}$ The present study demonstrated that the microhardness of the conventional dual-cure resin-based cement is greater than the self-adhesive cement. It could be due to the difference in the amount and size of fillers and monomers. The increased percentage of fillers in typical dual-cure resins is thought to be the cause of their higher microhardness. ${ }^{24}$ Alovisiet al. investigated the microhardness of two dual-cure resin cement with varying amounts of fillers light-cured through monolithic zirconia variations. They concluded that the microhardness was greater in dual-cure resin cement, having more filler contents. These results are in accordance with that of the present study. ${ }^{25,26}$

The present study found that the shade of the monolithic variant of zirconia significantly affected the microhardness of the dual-cure resin-based cement. The results are in accordance with the results of the study conducted by Passos et al. ${ }^{27}$ In another study conducted by Moreno et al., it was observed that the shade of the ceramic significantly affects the microhardness of the dualcure resin-based cement. ${ }^{28}$ On the contrary, the results of the study conducted by Kilinic et al. indicated the effect of shade of ceramic on the microhardness of the dual-cure resin-based cement. ${ }^{29}$ This is not in accordance with the results of our study.

According to the findings of this study, the water solubility and water sorption in conventional dual-cure resin-based cement were higher than self-adhesive dual-cure cement. The difference may be due to the difference in the percentage of 2-hydroxyethyl methacrylate (HEMA). It is usually believed that the cement in which HEMA amount is more significant, the water solubility is observed more. ${ }^{30}$ The results of our study are in accordance with the results of the study conducted by Aguiar et al. ${ }^{31}$ Moreover in our study, it was observed that the shade of the monolithic variant of the zirconia does not significantly affect the water sorption and water solubility of dual-cure resin cement. Kim et al. conducted a study and found that the results are in accordance with our study. ${ }^{32}$

The quantity of polymerization in resin-based cement affects their clinical effectiveness for a more extended period. It is believed that the measurement of microhardness is a reliable and straightforward process for evaluating the amount of polymerization of the resin-based cement. Since very few studies have been conducted to assess the effect of shade of monolithic variant of zirconia over the microhardness of the dual-cure resinbased cement, ${ }^{33}$ the current study analyzed the impact of different shades of monolithic variants of zirconia over the microhardness and the water solubility and water sorption of dual-cure resin cement underlying these restorations.

One of the limitations of this study was the use of a flat type of monolithic variant of zirconia. On the contrary, this flat condition is not observed in clinical situations due to occlusal cusps. ${ }^{34}$ Therefore, the study results may not be similar to that of the results observed clinically. Another limitation was that the effect of saliva on the water solubility and water sorption of the cement was not considered. Therefore, more studies should be carried out, which should evaluate the impact of the anatomy of tooth and saliva.

\section{Conclusion}

The effect of shade of monolithic variant of zirconia was significant over microhardness of both dual-cure resin-based cement. However, the result was not significant over the water solubility and water sorption of the resin-based cement. Further, it was also observed that the use of a monolithic variant of zirconia led to a decrease in the microhardness of both dual resin-based cement in comparison to the condition when no ceramics were used. Microhardness was more excellent in conventional resin-based dual-cure cement in comparison with self-adhesive dual-cure cement. At the same time, the water solubility and water sorption were lower in traditional dual-cure resin-based cement as compared to the self-adhesive dual-cure resin cement.

\section{References}

1. Malkondu O, Tinastepe N, Kazazoglu E. Influence of type of cement on the color and translucency of monolithic zirconia. J Prosthet Dent 2016;116(6):902-908. DOI: 10.1016/j.prosdent.2016.05.001.

2. Bavbek NC, Roulet JF, Ozcan M. Evaluation of microshear bond strength of orthodontic resin cement to monolithic zirconium oxide as a function of surface conditioning method. J Adhes Dent 2014;16(5):473-480. DOI: 10.3290/j.jad.a32812.

3. Sun T, Zhou S, Lai R, et al. Load-bearing capacity and the recommended thickness of dental monolithic zirconia single crowns. J Mech Behav Biomed Mater 2014;35:93-101. DOI: 10.1016/j. jmbbm.2014.03.014.

4. Nakamura K, Mouhat M, Nergård JM, et al. Effect of cement on fracture resistance of monolithic zirconia crowns. Acta Biomater Odontol Scand 2016;2(1):12-19. DOI: 10.3109/23337931.2015.1129908.

5. Flinn BD, Raigrodski AJ, Mancl LA, et al. Influence of aging on flexural strength of translucent zirconia for monolithic restorations. J Prosthet Dent 2017;117(2):303-309. DOI: 10.1016/j.prosdent.2016.06.010.

6. Khaledi AA, Vojdani M, Farzin M, et al. The effect of sintering time on the marginal fit of zirconia copings. J Prosthodont 2019;28(1):e285e289. DOI: 10.1111/jopr.12731.

7. Ladha K, Verma M. Conventional and contemporary luting cement: an overview. J Indian Prosthodont Soc 2010;10(2):79-88. DOI: 10.1007/ s13191-010-0022-0.

8. Gaonkar SH, Aras MA, Chitre V. An in vitro study to compare the surface roughness of glazed and chairside polisheddental monolithic zirconia using two polishing systems. J Indian Prosthodont Soc 2020;20(2):186-192. DOI: 10.4103/jips.jips_339_19.

9. Sulaiman TA, Abdulmajeed AA, Donovan TE, et al. Degree of conversion of dual-polymerizing cement light polymerized through monolithic zirconia of different thicknesses and types. J Prosthet Dent 2015;114(1):103-108. DOI: 10.1016/j.prosdent.2015.02.007.

10. Jafari $Z$, Alaghehmand $H$, Samani $Y$, et al. Light transmittance of CAD/CAM ceramics with different shades and thicknesses and microhardness of the underlying light-cured resin cement. Restor Dent Endod 2018;43(3):e27. DOI: 10.5395/rde.2018.43.e27.

11. Giti R, Zarkari R. The effect of a zirconia primer on the shear bond strength of Y-TZP ceramic to three different corematerials by using a 
self-adhesive resin cement. J Indian Prosthodont Soc 2019;19(2):134140. DOI: 10.4103/jips.jips_348_18.

12. Borse $\mathrm{S}, \mathrm{Chaware} \mathrm{SH}$. Tooth shade analysis and selection in prosthodontics: a systematic review and meta-analysis. J Indian Prosthodont Soc 2020;20(2):131-140. DOI: 10.4103/jips.jips_399_19.

13. Majumder A, Giri T, Mukherjee S. An in vitro study to compare the influence of different all-ceramic systems on the polymerization of dual-cure resin cement. J Indian Prosthodont Soc 2019;19(1):58-65. DOI: 10.4103/jips.jips_262_18.

14. Tavangar MS, Jafarpur D, Bagheri R. Evaluation of compressive strength and sorption/Solubility of four luting cement. J Dent Biomater 2017;4(2):387-393. PMID: 28959770; PMCID: PMC5608068.

15. Giti R, Vojdani M, Abduo J, et al. The comparison of sorption and solubility behavior of four different resin luting cement in different storage media. J Dent (Shiraz) 2016;17(2):91-97. PMID: 27284553; PMCID: PMC4885678.

16. Sadighpour L, Fazel A, Geramipanah F, et al. Effect of resin cement mixing method on the retention strength of a CAD/CAM zirconia crowns. J Indian Prosthodont Soc 2014;14(Suppl. 1):31-36. DOI: 10.1007/s13191-014-0355-1.

17. Çetindemir $A B$, Şermet $B$, Öngül $D$. The effect of light sources and CAD/CAM monolithic blocks on degree of conversion of cement. J Adv Prosthodont 2018;10(4):291. DOI: 10.4047/jap.2018.10.4.291.

18. Mendes LC, Matos IC, Miranda MS, et al. Dual-curing, self-adhesive resin cement: Influence of the polymerization modes on the degree of conversion and microhardness. Mater Res 2010;13(2):171-176. DOI: 10.1590/S1516-14392010000200009.

19. Jain NV, Dugal R, Madanshetty P, et al. Influence of different ceramic systems on the polymerization of dual-cured resin cement evaluated immediately and after 24 hours: an in vitro study. Int J Prosthodont Restor Dent 2015;5(1):1-9. DOI: 10.5005/jp-journals-10019-1121.

20. Kim HJ, Bagheri R, Kim YK, et al. Influence of curing mode on the surface energy and sorption/solubility of dental self-adhesive resin cement. Materials (Basel) 2017;10(2):129-142. DOI: 10.3390/ma10020129.

21. Samimi P, Kaveh S, Khoroushi M. Effect of delayed light-curing through a zirconia disc on microhardness and fracture toughness of two types of dual-C. J Dent Tehran Univ Med Sci 2019;15(6):339-350. PMID: 30842794; PMCID: PMC6399458.

22. Alovisi M, Scotti N, Comba A, et al. In fluence of polymerization time on properties of dual-curing cement in combination with high translucency monolithic zirconia. J Prosthodont Res 2018;62(4):468472. DOI: 10.1016/j.jpor.2018.06.003.
23. Gültekin P, Tunç EPAK, Öngül D, et al. Curing efficiency of dual-cure resin cement under zirconia with two different light curing units. $J$ Istanb Univ Fac Dent 2015;49(2):8-16. DOI: 10.17096/jiufd.97059.

24. Tagami A, Takahashi R, Nikaido $T$, et al. The effect of curing conditions on the dentin bond strength of two dual-cure resin cement. J Prosthodont Res 2017;61(4):412-418. DOI: 10.1016/j. jpor.2016.12.012.

25. Kilinc E, Antonson SA, Hardigan PC, et al. The effect of ceramic restoration shade and thickness on the polymerization of lightand dual-cure resin cement. Oper Dent 2011;36(6):661-669. DOI: 10.2341/10-206-L.

26. Pazin MC, Moraes RR, Gonçalves LS, et al. Effects of ceramic thickness and curing unit on light transmission through leucite-reinforced material and polymerization of dual-cured luting agent. J Oral Sci 2008;50(2):131-136. DOI: 10.2334/josnusd.50.131.

27. Borges GA, Agarwal P, Miranzi BA, et al. Influence of different ceramics on resin cement knoop hardness number. Oper Dent 2008;33(6):622628. DOI: 10.2341/07-155.

28. Fonseca RG, Santos JG, Adabo GL. Influence of activation modes on diametral tensile strength of dual-curing resin cement. Braz Oral Res 2005;19(4):267-271. DOI: 10.1590/s1806-83242005000400006.

29. Duran I, Kaleli N, Ural Ç, et al. Evaluation of the light transmission of chairside polymer infiltrated hybrid ceramics in different shades and thicknesses. J Appl Biomater Funct Mater 2019;17(1): 2280800018807109. DOI: 10.1177/2280800018807109.

30. Passos SP, Kimpara ET, Bottino MA, et al. Effect of ceramic shade on the degree of conversion of a dual-cure resin cement analyzed by FTIR. Dent Mater 2013;29(3):317-323. DOI: 10.1016/j.dental.2012.11.014.

31. Sokolowski G, Szczesio A, Bociong K, et al. Dental resin cementthe influence of water sorption on contraction stress changes and hydroscopic expansion. Materials (Basel) 2018;11(6):973-988. DOI: 10.3390/ma11060973.

32. Aguiar TR, André CB, Ambrosano GM, et al. The effect of light exposure on water sorption and solubility of self-adhesive resin cement. Int Sch Res Notices 2014;2014:610452. DOI: 10.1155/2014/610452.

33. Meşe A, Burrow MF, Tyas MJ. Sorption and solubility of luting cement in different solutions. Dent Mater J 2008;27(5):702-709. DOI: 10.4012/ dmj.27.702.

34. Shiozawa M, Takahashi H, Asakawa $\mathrm{Y}$, et al. Color stability of adhesive resin cement after immersion in coffee. Clin Oral Investig 2015;19(2):309-317. DOI: 10.1007/s00784-014-1272-8. 